\title{
Editorial
}

The current issue developed and brought together by Daniel Steere is an excellent array of papers which bring additional insight to understanding Community Based Instruction. Many experienced educators and rehabilitation specialists, as well as parents, have realized for years, that community based training is a most effective way to provide instruction to individuals with significant intellectual disabilities. The approach when coupled with several of the key principles of curriculum design discussed in this editorial are the core of what works most effectively in training individuals with significant intellectual disabilities.

There are any of a number of approaches to designing a curriculum, from the purchase of commercially available 'canned' programs to those which are more 'homemade' in nature. Many agencies or schools also utilize a standardized curriculum that all trainers must follow. In some cases, state departments of education have mandated that certain types of curricula be utilized for students which can then presumably lead to passing of competency tests or literacy types of tests. These differing approaches to curriculum design are one of the reasons that many students leave school without the necessary independent living skill building blocks that are essential for competence in today's society. However, in order to truly achieve the level of continuity across the age groups in school for the purpose of having a genuine longitudinal curriculum there are several key tenets which need to be followed. These items include:

(1) Individualized and person-centered approach

(2) Functional or practical curriculum
(3) Adaptive curriculum

(4) Ecologically oriented curriculum

\section{Individualized and person-centered}

Each person requires a specialized set of instructional objectives that area particularly suited for his or her needs. In all too many training settings there are Individual Education or Service Plans that are written which are virtually identical in their content and scope. This type of 'blanket' programming does a grave injustice to an individual's particular needs. We should not assume, for example, that all 16-year-olds with a label of educational mental retardation should learn the capitals of all 50 states. It may be that this is an inappropriate instructional objective for all of these students On the other hand, there may be a justification for one or two to be learning something like this in the academic area because they have hopes of going on to community college.

In recent years the concept of person-centered planning has become increasingly popular. Person-centered planning provides an indepth look at a given student and his or her world, particularly home and community with a special focus on what their vision is for the future. The concept of person-centered planning is especially important for children who especially need a road map of what the future can hold for them. It is the primary theme of this issue that longitudinal curriculum is the best way to provide educational programming to children with special needs. A person-centered planning approach is highly consistent with this type of long-term curriculum planning. The absence of this form of individual- 
ized person-centered planning has unfortunately been the hallmark of many special education programs, thereby depriving students with disabilities of an opportunity to reach their fullest potential.

\section{Functional or practical}

The second issue which all curriculum objectives should have for students, regardless of their disability or level of disability, is one that is functional or practical in nature. A functional curriculum has been written about quite extensively in recent years, but many schools still continue to provide non-functional instructional objectives to the long-term disadvantage of the students. There is nothing especially complicated about designing and implementing functional objectives. What is involved is a careful analysis of the individualized and person-centered needs for each student and then weighed in the context of what does this student need the most. In specific terms, this often means what the student will be able to utilize the most and what will help him or her make their life less challenging and make them more competent.

The functional aspects of an individual's curriculum cannot be emphasized enough. No matter how good the quality of instruction or how sophisticated the equipment or how new the school facilities, if the student is receiving instruction, in inappropriate subject matter, then he or she will have missed the opportunity to be benefitting from more useful instruction. A good case and point might involve the teenager with severe mental retardation and some slight physical disability and cerebral palsy. Assume this student who we will call Mike has had an IEP objective to tie his shoelaces into a knot. Assume further that Mike has attempted to learn this for over the last 5 years, pretty much unsuccessfully, why would any teacher continue to teach this skill when alternative types of shoes might be utilized or ways to fasten the shoe? Good common sense would suggest that Mike needs to be learning some other skills that will allow him to be competent at home and in the community, rather than spending day after day with, at best, marginal success on a skill that does not play away his strengths or most pressing needs.
There are hundreds of persons like Mike who can be identified for any type of disability or level of disability. The key question that the teacher must ask the student and the family is what are the activities that your son or daughter need the most in order to be effective and competent as a human being in the weeks and months ahead? If families have at times unrealistic appraisals of these expectations, then the teacher must work carefully with them in an educative fashion to suggest other alternative goals.

\section{Adaptive}

In addition to these first two important principles of curriculum design there is a strong need for a curriculum to be adaptive to the specific goals and capabilities of a given student. On one hand it should be obvious that in order to provide an individualized and functional type of curriculum certain adaptations will be necessary On the other hand, this principle of curriculum design also suggests that a goal that has been identified with the IEP committee at the beginning of the school year as one of the curriculum objectives may have to be altered two or three months later. If all are in agreement that a modified curriculum objective makes sense, then there is nothing wrong whatsoever with changing the goal. It is much more problematical to readily continue to provide instructional service to students who are not learning because the objective is inappropriate. One of the key points that an instructor must remember, however, is that it may take some time before a decision can be definitively made to adapt the objective. It may very well be that the general area of curriculum is most appropriate (functioning independently in the community for example), but that riding a bus is not the right target objective at this point and instead crossing the street might be more appropriate. This type of adaptation is even more essential for students who are more sophisticated in terms of cognitive problem solving and academics. The resource teacher who is working with a student to improve their reading skills must be flexible enough to make a change in the goals that are being targeted if the student is becoming increasingly frustrated due to failure. This also applies to learning 
computer skills, calculation, arithmetic skills, or improving ones handwriting. The inability to continually modify the goals is a problem which some teachers have because they are too rigid or do not wish to take the time to go through the often lengthy process of deciding what new objectives to work on with the student.

Adaptive curriculum instruction has been shown to be a very effective way of providing instruction for students with significant disabilities. In this issue we will heavily focus upon using an adaptation approach to helping students learn the curriculum objectives to their fullest potential. Each of the curriculum objectives identified in this issue, are subject to adaptation and redesign based on what the student's needs are. The teacher must, however, be thinking in terms of the need to adapt when the student is continuing to have problems in acquiring the skills that have been originally targeted.

\section{Ecologically oriented}

For almost 20 years now there has been an increasing understanding of the importance of examining the student's environments when making decisions about what are the most important skills to teach. Two decades later these ideas are still more viable than ever, especially when complimented with person-centered planning, functional instruction, and adaptation. The underlying notion of an ecologically oriented program requires the student, teacher, and family to sit down and discuss what the high priority activities are and each of the major living environments for the students. For example, what are the main activities that the student performs at home and in his immediate neighborhood? What are the major activities that the student performs or wishes to perform in the community, such as going to church, going grocery shopping, going to the shopping mall, etc.? What are the major recreational activities that the student is involved in or would like to become involved in? There are many different potential environments that can be analyzed for different types of activities. These activities then make up the foundation for what the different curriculum objectives would be.
Therefore, if a student goes with his father to church every Saturday morning to participate in a breakfast men's luncheon, one activity the student might need to learn how to perform best would be clean-up activities. This would be an example of an area where the student could be helpful to the father and still participate with other adults in a meaningful activity.

There is no end to the different objectives that can be identified using an ecologically oriented approach. This approach has usually been seen as being most viable for those with the most severe intellectual disabilities, but this is not really the case. Any student with a disability is going to have some skill deficits within other environments outside of the school, and it is up to the teacher and student, along with the family to make some decisions about what is the highest priority of different skills to focus upon in the coming school year.

As we review these four principles of curriculum design, individualized and person-centered planning, functional or practical curriculum, adaptive instruction, and ecologically oriented curriculum, we can see that these are the glue that hold the longitudinal curriculum design together. In order to provide the continuity of instructional service across the different age levels, these tenets must be followed and understood by all participating in the educational process. Given the fact that some teachers will not always 'buy in' to these ideas, parents will sometimes have to take a larger proportion of the responsibility, but long-term school as opposed to individual teachers must have a longitudinal curriculum philosophy which teachers and administrators will ultimately adhere to.

In this issue of the Journal of Vocational Rehabilitation there are numerous papers about how to implement curriculum and curriculum objectives, but running through all of the articles are the major principles which are critical for effective learning by students and competence in their behavior. Community based instruction is a good strategy. It needs to be used more. 